\title{
Correction to: Agroforestry suitability mapping of India: geospatial approach based on FAO guidelines
}

\author{
Firoz Ahmad (1) - Md Meraj Uddin • Laxmi Goparaju
}

Published online: 29 June 2018

(C) Springer Nature B.V. 2018

\section{Correction to: Agroforest Syst https://doi.org/10.1007/s10457-018-0233-7}

Unfortunately, in the original publication of the article, in Abstract and Results and discussion some percent values are written incorrectly.

In Abstract the 4th sentence was written as 'The analysis of land potentiality in India for agroforestry suitability reveals $32.8 \%$ as highly suitable (S1), $40.4 \%$ moderately suitable (S2), $11.7 \%$ marginally suitable (S3), and $9.1 \%$ not suitable (NS)' in original article.

It should be corrected as

'The analysis of land potentiality in India for agroforestry suitability reveals $37.4 \%$ as highly suitable (S1), 41.8\% moderately suitable (S2), 11.7\% marginally suitable (S3), and 9.1\% not suitable (NS).'

In Results and discussion the 1st sentence was written as "Agroforestry suitability maps generated for the whole India showed $32.8 \%$ as highly suitable, $40.4 \%$ as moderately suitable, $11.7 \%$ as marginally suitable, and $9.1 \%$ as not suitable (Table 3; Fig. 11).' in original article.

It should be corrected as

'Agroforestry suitability maps generated for the whole India showed $37.4 \%$ as highly suitable, $41.8 \%$ as moderately suitable, $11.7 \%$ as marginally suitable, and 9.1\% as not suitable (Table 3; Fig. 11).'
A3 F. Ahmad $(\bowtie) \cdot$ L. Goparaju

A4 Vindhyan Ecology and Natural History Foundation,

A5 Mirzapur, Uttar Pradesh, India

A6 e-mail: adfiroz@yahoo.com

A7 M. M. Uddin

A8 University Department of Mathematics, MCA, Ranchi

A9 University, Ranchi, Jharkhand, India 